\title{
Eco-efficiency in Portuguese companies of marble sector
}

\author{
Justina Catarino*, João Henriques ${ }^{1}$ and Anabela Maia \\ LNEG - Estrada do Paço do Lumiar, 1649-038 Lisboa, Portugal
}

(Received 6 January 2014; accepted 11 April 2015)

\begin{abstract}
The activities developed within an eco-efficiency project in mineral industries located in the largest area for marble extraction in Portugal, in Alentejo region, in the Estremoz - Borba and Vila Viçosa anticline are presented in this paper. The project was designed to apply the sustainability concept in seven companies of marble extraction and transformation. The adopted strategy used new cleaner production models together with sustainable value (SV) improvement, leading to the rationalization of the industrial process, the involvement of economic agents and the orientation of the management of production processes towards eco-efficiency. The challenge was to have the mineral industry managing efficiently the resources on which the business depends, according to sustainability principles. Different opportunities for improvement, related to the minimization of materials, water and energy use, were identified in the companies. Some proposals mainly related to social improvement and small and medium-sized enterprise competitiveness benefits were also selected and discussed. This approach allows the integration of sustainability at company's and region's levels by combining in the entrepreneurial activity the creation of wealth together with the environment protection and the achieving of social benefits. Highlights: The involvement of different stakeholders in the project (Eco-efficiency in Portuguese companies of marble sector) was positive in the discussion and search of solutions for companies. It is possible to involve marble extraction and processing companies in eco-efficiency improvement towards sustainability. Companies from the marble sector improved environmental and social performance and reduced the costs of their production processes by applying SV methodology.
\end{abstract}

Keywords: eco-efficiency; sustainable value; marble sector; ornamental stone

\section{Introduction}

\subsection{Sustainability in the mineral sector}

Mineral extraction activities, by providing raw materials, play an important part in a country economical position but they also represent environmental negative effects for local communities and the landscape. Marble, used in construction, is one of those materials, being its production limited to a certain number of countries. The European Union (EU) supplies represent about 17\% of world extraction (Traverso, Rizzo, and Finkbeiner 2010).

Although the negative impacts have been detected long ago, nowadays there is a progressive awareness from entrepreneurs in order to minimize them in the mineral extraction and processing activities. The concern about sustainable development, defined by Word Business Council for Sustainable Development (2006) as forms of progress that meet the needs of the present without compromising the ability of future generations to meet their needs, is not a new one for the sector that has always been appointed by the impacts of its activities either at the environment or social levels.

Wherever mineral extraction exists, it will affect to a certain extent either environment or local communities. Anyway those impacts can be minimized, if the enterprises adopt a responsible behaviour towards resource exploitation and transformation and all the stakeholders (Miranda, Chambers, and Coumans 2005).

In spite of the unquestionable importance of the mineral industry to the countries' development, governments must assure that mineral resource exploitation respects environment, human rights and society in a general way and does not consider only economic aspects. More often than desirable the harmful effects of an irresponsible exploitation of resources can be seen, thus risking the well-being of present and future generations (United Nations 2003).

The challenge is to have the extraction industry together with the processing of the raw materials managing efficiently the resources on which the business depends, according to sustainability principles, and therefore the importance of research and implementation of innovative approaches, involving the different stakeholders in the discussion and search of solutions for the companies and regions.

\subsection{The Portuguese marble scenario}

Portugal is one of the main world producers of ornamental stones. After Italy, Portugal is the bigger world exporter per capita, China, France, Spain and Saudi Arabia being the main importers (AICEP 2012). Marble and limestone

\footnotetext{
*Corresponding author. Email: justina.catarino@lneg.pt
} 